Pacific Journal of Mathematics

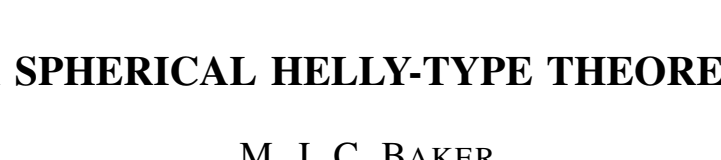




\title{
A SPHERICAL HELLY-TYPE THEOREM
}

\author{
M. J. C. BAKER
}

The purpose of this paper is to prove for all positive integers $n$ and $r$ that if a family of $n+1+2 r$, or more, strongly convex sets on the $n$ dimensional sphere $S_{n}$ is such that each intersection of $n+1+r$ of them is empty, then the intersection of some $n+1$ of them must be empty. $\quad\left(S_{n}\right.$ is the set of points in $n+1$ dimensional Euclidean space satisfying $x_{1}^{2}+x_{2}^{2}+\cdots+x_{n+1}^{2}=1$. A set on a sphere is called strongly convex if it does not contain any pair of diametrically opposite or antipodal points, and if together with any two of its points it contains the whole of the minor arc of the great circle joining them.)

In a previous paper [1] I established the result for the special case $r=1$. The present theorem, while more general, has a simpler proof. Theorems of a somewhat similar nature have been established by Robinson [5] using a different definition of convexity. A survey of Helly-type theorems together with a full bibliography is to be found in Danzer, Grünbaum and Klee [2]. As before, the proof depends on the following theorems:

THEOREm 1. (Separation) [4]. Two disjoint closed strongly convex sets on a sphere can be strictly separated by a hyperplane through the centre.

THEOREM 2. (Molnár) [3]. If a family of closed strongly convex sets on an $n$ dimensional sphere is such that no $n+2$ of them cover the sphere and each intersection of $n+1$ of them is nonempty, then the intersection of them all is nonempty.

The result is first proved for $n+1+2 r$ closed sets.

Lemma. For all positive integers $n$ and $r$, if a family of $n+1+2 r$ closed strongly convex sets on $S_{n}$ is such that each intersection of $n+1$ of them is nonempty, then the intersection of some $n+1+r$ of them must be nonempty.

Proof. Let $A \cdots Z$ be a family of $n+1+2 r$ closed strongly convex sets on $S_{n}$ such that

(1) each intersection of $n+1+r$ of them is empty and

(2) no intersection of $n+1$ of them is empty: 
we shall obtain a contradiction.

The $n+1+r$ sets $A \cdots P$ (say) have empty intersection (1) and so, by Molnár's theorem,

(3) some $n+2$ of them cover the $S_{n}$; for otherwise some intersection of $n+1$ of them would be empty, contradicting (2).

Let $x$ be any point on the $S_{n}$. By (3) $x$ must lie in at least one of the $n+1+r$ sets $A \cdots P$. Suppose, without loss of generality, that $x \in A$. A similar argument shows that $x$ belongs to at least one of the $n+1+r$ sets $B \cdots Q$; to $B$, say. Repeating this procedure until all the sets $Q \cdots Z$ have been used, it follows that $x$ is in at least $r+1$ of $A \cdots Z$.

(4) Thus any point of the $S_{n}$ is in at least $r+1$ of $A \cdots Z$.

(5) Moreover, no point can be in more than $r+n$ sets, for if there were such a point, the antipodal point which could not belong to any of the same sets, would have to belong to less than $r+1$ sets since there are only $n+1+2 r$ available; and this contradicts (4).

Now consider a great $S_{n-1}$ not intersecting $A$. There must be one since $A$ is strongly convex, and therefore $A$ and $-A$ are disjoint and closed and convex, and can therefore by the separation theorem be strictly separated by a hyperplane through the centre.

Every point on the $S_{n-1}$ must, by (4), belong to at least $r+1$ of the sets $B \cdots Z$, and can belong at most to $r+n-1$ by a similar argument to that at (5) except that this time there are only the $n+2 r$ sets $B \ldots Z$ available. The intersections of these sets with the $S_{n-1}$ are closed and strongly convex, so there is a great $S_{n-2}$ on the $S_{n-1}$ which does not meet $B$.

The procedure is repeated until finally we have a great circle not meeting any of the $n-1$ sets $A \cdots F$ (say). Those parts of the $2+2 r$ sets $G \cdots Z$ that lie on the circle are still closed and strongly convex. Consider now a pair of antipodal points neither of which is in $G$. These are points of the original $S_{n}$ and so by (4) must each belong to $r+1$ of the sets $A \cdots Z$. But the $n$ sets $A \cdots G$ are, by construction, not available; so, of the original $n+1+2 r$ sets, only $2 r+1$ are left. None of these can contain both antipodal points. Thus a contradiction of (4) has been obtained and the lemma established.

The extension to a family of sets whether closed or not is routine. It may be found for example in [1] if the appropriate substitutions are made.

Finally if the family has more than $n+1+2 r$ sets and satisfies the rest of the hypothesis the result follows immediately by considering 
just $n+1+2 r$ of the sets. This completes the proof of the theorem.

Note. If a closed strongly convex set is defined to be the intersection of open hemispheres, instead of by the equivalent conventional definition used here, then the separation theorem may be dispensed with in the proof.

\section{REFERENCES}

1. M. J. C. Baker, A Helly-type Theorem on a sphere, J. Austral. Math. Soc. 8 (1967), 323-326.

2. L. Danzer, B. Grünbaum and V. Klee, Helly's Theorem and its Relatives, in Convexity, being the Proceedings of the Seventh Symposium in Pure Mathematics of the American Mathematical Society, A. M. S., Providence, R. I., 1963, 101-180.

3. J. Molnár, Über eine Übertragung des Hellyschen Satzes in sphärische Räume, Acta Math. Acad. Sci. Hungary 8 (1957), 315-318.

4. B. C. Rennie, unpublished paper.

5. C. V. Robinson, Spherical theorems of Helly-type and Congruence indices of spherical caps, Amer. J. Math. 64 (1942), 260-272.

Received August 5, 1966.

RAAF ACADEMY

POINT COOK, VICTORIA

Australia 



\section{PACIFIC JOURNAL OF MATHEMATICS}

\section{EDITORS}

\section{H. ROYDEN}

Stanford University

Stanford, California

J. P. JANS

University of Washington

Seattle, Washington 98105

\section{J. DUGUNDJI}

Department of Mathematics

Rice University

Houston, Texas 77001

RICHARD ARENS

University of California

Los Angeles, California 90024

ASSOCIATE EDITORS

E. F. BECKENBACH

B. H. NeumanN

F. WoLF

K. YosidA

\section{SUPPORTING INSTITUTIONS}

\author{
UNIVERSITY OF BRITISH COLUMBIA \\ CALIFORNIA INSTITUTE OF TECHNOLOGY \\ UNIVERSITY OF CALIFORNIA \\ MONTANA STATE UNIVERSITY \\ UNIVERSITY OF NEVADA \\ NEW MEXICO STATE UNIVERSITY \\ OREGON STATE UNIVERSITY \\ UNIVERSITY OF OREGON \\ OSAKA UNIVERSITY \\ UNIVERSITY OF SOUTHERN CALIFORNIA
}

\author{
STANFORD UNIVERSITY \\ UNIVERSITY OF TOKYO \\ UNIVERSITY OF UTAH \\ WASHINGTON STATE UNIVERSITY \\ UNIVERSITY OF WASHINGTON \\ AMERICAN MATHEMATICAL SOCIETY \\ CHEVRON RESEARCH CORPORATION \\ TRW SYSTEMS \\ NAVAL ORDNANCE TEST STATION
}




\section{Pacific Journal of Mathematics}

\section{Vol. 23, No. 1 \\ March, 1967}

M. J. C. Baker, A spherical Helly-type theorem ................... 1

Robert Morgan Brooks, On locally m-convex*-algebras.............. 5

Lindsay Nathan Childs and Frank Rimi DeMeyer, On automorphisms of separable algebras ...................................

Charles L. Fefferman, A Radon-Nikodym theorem for finitely additive set

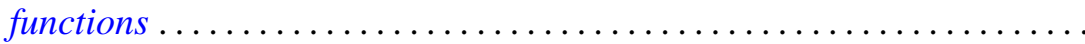

Magnus Giertz, On generalized elements with respect to linear

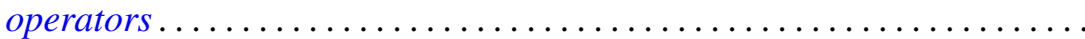

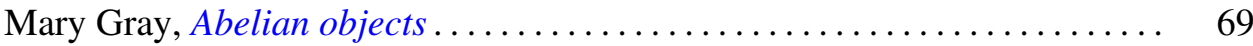

Mary Gray, Radical subcategories.............................. 79

John A. Hildebrant, On uniquely divisible semigroups on the two-cell . . . . . 91

Barry E. Johnson, AW*-algebras are $\mathrm{QW}^{*}$-algebras ............... 97

Carl W. Kohls, Decomposition spectra of rings of continuous functions . . . . 101

Calvin T. Long, Addition theorems for sets of integers .............. 107

Ralph David McWilliams, On $w^{*}$-sequential convergence and quasi-reflexivity ................................... 113

Alfred Richard Mitchell and Roger W. Mitchell, Disjoint basic

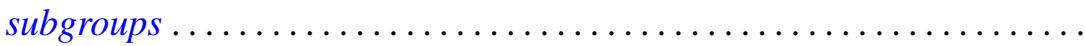

John Emanuel de Pillis, Linear transformations which preserve hermitian and positive semidefinite operators .

Qazi Ibadur Rahman and Q. G. Mohammad, Remarks on Schwarz's lemma

Neal Jules Rothman, An $L^{1}$ algebra for certain locally compact topological semigroups ...

F. Dennis Sentilles, Kernel representations of operators and their adjoints ...

D. R. Smart, Fixed points in a class of sets

K. Srinivasacharyulu, Topology of some Kähler manifolds

Francis C.Y. Tang, On uniqueness of generalized direct decompositions .

171 Albert Chapman Vosburg, On the relationship between Hausdorff dimension and metric dimension . 